\title{
A inclusão no mercado de trabalho de pessoas com deficiências através de programas de aprendizagem: estudo de caso
}

\section{The inclusion of the people with disabilities in the labor market through learning programs: case study.}

\author{
Renata Souza da Silva \\ Centro Universitário UNA -Belo Horizonte - Brasil \\ re-ge@hotmail.com \\ Cristiana Trindade Ituassu \\ Centro Universitário UNA -Belo Horizonte - Brasil \\ cristianaituassu@yahoo.com.br \\ Iris Barbosa Goulart \\ Centro Universitário UNA -Belo Horizonte - Brasil \\ irisbgoulart@gmail.com
}

\section{Resumo}

Este trabalho tem por objetivo analisar como são feitos a inclusão e o desenvolvimento de jovens aprendizes com deficiência no mercado de trabalho. A pesquisa foi realizada em uma empresa da região metropolitana de Belo Horizonte. Abordou-se a conceituação deficiência e a produção científica sobre a inclusão de pessoas com deficiências no mercado de trabalho, tanto sob o aspecto legal, quanto sob o aspecto de sua aceitação. Foi desenvolvida uma pesquisa qualitativa, que consistiu num estudo de caso de caráter descritivo, e utilizou-se como instrumento de coleta uma entrevista semiestruturada, sendo 24 os sujeitos de pesquisa, dos quais nove eram jovens com deficiência que atuaram como jovens aprendizes de rotinas administrativas, oito gestores e sete colegas de trabalho desses jovens. Verificou-se que os jovens aprendizes demonstraram satisfação e orgulho por terem participado de um projeto de aprendizagem e evidenciaram sentimentos de autovalorização, autoestima mais elevada ao conviverem com outras pessoas e poderem utilizar o aprendizado adquirido. Gestores e colegas de trabalho alegaram que o processo de inclusão de pessoas com deficiência no trabalho traz benefícios, tanto para o jovem com deficiência, quanto para a empresa nos quesitos: aprendizagem, desenvolvimento, convívio e crescimento profissional.

Palavras-chave: pessoas com deficiência, qualificação de pessoas com deficiência, inclusão de pessoas com deficiência no mercado de trabalho.

\section{Abstract}

This work aims to analyze how the inclusion and development of young learners with disabilities in the labor market is made. The survey was conducted at a company in the metropolitan region of Belo Horizonte. It was approached the disability conceptualization and the scientific production about the inclusion of people with disabilities in the labor 
market, both in legal aspect as in respect of acceptance. A qualitative research was developed, which consisted of a descriptive case study, and it was used a semi-structured interview as a collection instrument, with 24 researched individuals, of which 09 were young individuals with disabilities who acted as young apprentices in administrative routines, 08 were managers and 07 were co-workers of these young individuals. It was found that the young apprentices were satisfied and proud for taking part in the learning project, and showed feelings of self-worth and higher self-esteem for get along with other people and being able to use the knowledge acquired. Managers and co-workers claimed that the inclusion process of disabled people at work brings benefits both for the young disabled person and for the company, in the categories: learning, development, conviviality and professional growth.

Keywords: people with disabilities, disabled people qualification, disabled people inclusion in the labor market.

\title{
1. Introdução
}

Os estudos sobre inserção, desenvolvimento e gestão do trabalho de pessoas com deficiência incluem-se no campo de investigações sobre a diversidade (SUZANO et al., 2008). Segundo Mendonça (2010, p. 23), a história revela os mais diversos tratamentos às pessoas com deficiência que vão desde atitudes de aceitação até atitudes de abandono, segregação e destruição.

É recente a abertura do mercado de trabalho para pessoas com deficiência como observa Lorentz (2006, p. 86).

\begin{abstract}
Ao longo da história, a pessoa com deficiência foi tratada, ora como empecilho real à produção de prole saudável, o que redundou em políticas de sua pura e simples eliminação, como motivo de escárnio, objeto de punição divina por erros cometidos, como afeta à condução de práticas religiosas, inspiradora de caridade, de assistência, de misericórdia piedosa, ora como pessoa que deveria ser "tolerada" ou "consertada" e, mais recentemente, como ser que tem direito ao mesmo respeito e dignidade que qualquer outro cidadão.
\end{abstract}

No Brasil, a questão da inclusão de pessoas com deficiência obteve evidência no mundo empresarial a partir de 2003, quando foram aprovadas normas que visavam à imposição de multas administrativas às empresas pelo não cumprimento do sistema de cotas. Desde então, iniciou-se uma corrida pela busca do cumprimento dessas cotas, seja pelo temor da aplicação das multas administrativas, seja pela identificação com o propósito e com a causa da inclusão social. Diante do cenário apresentado, constata-se que a legislação que ampara os direitos das pessoas com deficiência traz um desafio novo para as organizações de trabalho (CARVALHO-FREITAS; MARQUES, 2010b). O desafio está lançado para gestores e empregadores, determinando o crescimento do interesse e a necessidade de se pesquisar a inserção, a inclusão, o desenvolvimento e a gestão do trabalho de pessoas com deficiência.

Estudos indicam que uma questão importante para o processo de inclusão de pessoas com deficiência nas organizações consiste em analisar como os gestores percebem a deficiência e como as pessoas com deficiência são vistas pelos colegas de trabalho. Além disso, as possibilidades de trabalho dessas pessoas e sua qualificação constituem elemento importante para a compreensão da dimensão da diversidade nas organizações e a maneira de administrá-la (CARVALHO-FREITAS; MARQUES, 2010a). Para a Organização Internacional do Trabalho (OIT), a pessoa com deficiência encontra dificuldade de inclusão no mercado de trabalho. "O indivíduo cujas perspectivas de obter emprego apropriado, reassumi-lo, mantê-lo e nele progredir são substancialmente reduzidas em virtude de deficiências física, auditiva, visual, mental ou múltipla 
devidamente reconhecidas, agravadas pelas dificuldades locais de inclusão no mundo do trabalho" (SECRETARIA INTERNACIONAL DO TRABALHO, 2006, p. 5).

No campo da gestão da diversidade, há estudos que apontam para três dificuldades para inserir e gerir o trabalho das pessoas com deficiência: as formas como os gestores veem a deficiência, a adequação das condições e práticas de trabalho por parte das empresas e a necessidade de avaliar a satisfação das pessoas com deficiências inseridas no mercado de trabalho (SUZANO et al., 2008).

Tanaka e Manzini (2005, p. 274) alertam sobre os impactos que a imposição da Lei de Cotas está causando no mercado de trabalho.

Com a exigência imposta pela lei começou a haver uma oferta crescente de vagas para pessoas com deficiência nas empresas, veiculada principalmente por meio da mídia, despertando a ilusória ideia de que, finalmente o mercado de trabalho estava receptivo a essa população. Apesar de essas leis terem funcionado como uma válvula impulsionadora para a abertura de vagas nas empresas, o número de pessoas com deficiência que ora está participando do mercado de trabalho, ao contrário, ainda está muito aquém do que ela prevê.

Outros autores também analisaram esse aspecto, elencando os efeitos e impactos no mercado de trabalho, com a imposição da Lei de Cotas.

A legislação existente não se preocupou com as regras do mercado e fez prevalecer à falsa concepção segundo a qual, colocando-se um dispositivo na lei, o portador de deficiência seria automaticamente inserido no trabalho produtivo (HEINSKI; BIGNETTI, 2002, p. 2).

Estudos sobre as possibilidades de inclusão das pessoas com deficiência nas organizações de Minas Gerais demonstram que a imposição legal de cotas não favorece a inclusão, constituindo, inclusive, fonte de resistência à política de inclusão (BATISTA, 2004).

De acordo com Sassaki (1999), historicamente a trajetória da pessoa com deficiência passou por quatro fases: a exclusão, a segregação, a integração e, por fim, a inclusão. O mesmo autor elucida o conceito de empresa inclusiva, considerando-a como aquela que acredita no valor da diversidade humana, contempla as diferenças individuais, efetua mudanças fundamentais nas práticas administrativas, implementa adaptações no ambiente físico, adapta procedimentos e instrumentos de trabalho, treina todos os recursos humanos na questão da inclusão.

Mendonça (2010) traz o conceito de empresa socialmente responsável, ou seja, aquela que passa a tratar a questão das cotas para as pessoas com deficiência como um compromisso social, esquecendo-se de fiscalizações e multas. Segundo Mendonça (2010, p. 174) "[...] a admissão de pessoas com deficiência impõe também modificações arquitetônicas, aquisição de equipamentos adaptados, treinamento dos candidatos à vaga, bem como adaptação daqueles que não possuem deficiência no convívio social com a diversidade".

A questão da inclusão das pessoas com deficiência ainda apresenta características segregatícias. O mercado de trabalho está exigente, e obstáculos tais como transporte não adaptado, falta de preparo escolar e profissional, barreiras sociais, entre outras, são vivenciadas pelas pessoas com deficiência (CARVALHO-FREITAS, 2009).

Lopes (2005) faz um alerta com relação ao direito de ir e vir, que limita a locomoção da pessoa com deficiência e restringe também a sua possibilidade de emprego. Segundo a autora, muitas pessoas com deficiência deixam de aceitar alguma oferta de emprego por não poderem se locomover dignamente para o local de trabalho.

O presente trabalho teve como objetivo analisar de que maneira vem se efetivando a inclusão e o desenvolvimento de jovens aprendizes com deficiência no mercado de 
trabalho. Buscou-se identificar a percepção das pessoas com deficiência sobre sua inclusão no mercado de trabalho, assim como a percepção de seus pares e de seus gestores de uma empresa de grande porte da região metropolitana de $\mathrm{BH}$, que admitiu em seus quadros pessoas com deficiência oriundas de um programa de aprendizagem.

\section{Revisão da literatura sobre o tema}

Ao longo da história, a pessoa com deficiência foi sendo tratada de diferentes modos, tendo variações até mesmo de terminologias empregadas para designar a sua condição. Sem ater-se ao resgate histórico, que se inicia na Antiguidade, este trabalho busca analisar o conceito de deficiência a partir do período contemporâneo e se detém na identificação dos tipos de deficiência.

No início dos tempos modernos, quando o trabalho do campo foi se transferindo para as fábricas situadas nas cidades, as pessoas com deficiência foram consideradas indivíduos não produtivos que oneram a sociedade, uma vez que requerem custos para o seu sustento e manutenção. Com os avanços da medicina moderna, o trato da deficiência deixou de ser visto como problema religioso e passou a ser considerado como problema médico (ARANHA, 2003).

A Idade Contemporânea, iniciada a partir da Revolução Francesa (1789, D.C.), foi inicialmente marcada pela corrente filosófica iluminista, que elevava a importância da razão. Nesse período, que abarca o desenvolvimento e a consolidação do regime capitalista no ocidente, o problema crucial passou a ser o próprio homem na sociedade. As atitudes para com as pessoas com deficiência se modificaram e passou-se a defender a responsabilidade pública pelas necessidades de tais pessoas, fortaleceu-se a discussão sobre o fato de a pessoa com deficiência ser cidadã como qualquer outra, sendo detentora dos mesmos direitos e oportunidades disponíveis na sociedade, independentemente do tipo e grau de comprometimento da deficiência (ARANHA, 2003).

Observa-se que, ao longo do tempo, foi se delineando um amadurecimento da sociedade para os tratamentos dados a pessoas com deficiência. Assim, essas pessoas que, em certo momento, foram vistas como inúteis, incapacitadas, passaram depois a constituir objeto de caridade e filantropia.

Sassaki (2009) apresenta os termos utilizados ao longo da história para se referir a pessoas com deficiência: inválidos, defeituosos, indivíduos com deformidade, excepcionais, deficientes e considera que todos esses termos são discriminatórios. Justifica-se, por isso, o uso da expressão pessoa com deficiência.

Oliveira, Goulart-Júnior e Fernandes (2009, p. 226) realizaram uma pesquisa para analisar alguns aspectos das políticas adotadas para emprego e inclusão de pessoas com deficiência nos Estados Unidos, na União Europeia e no Brasil, conforme exposto a seguir.

A definição de deficiência adotada no contexto dos Estados Unidos, descrita no ADA ("The American WithDisabilitiesAct"), relaciona-se a uma parcela populacional que vem enfrentando restrições vinculadas a uma história de tratamento desigual, baseado em estereótipos que não indicam a verdadeira contribuição desses indivíduos como participantes da sociedade. Já no "EuropeanActionPlan", documento relativo à política adotada na União Europeia, não há uma conceituação exata para o termo, porém o posicionamento contrário ao assistencialismo e a defesa do convívio e participação ativa da pessoa com deficiência na sociedade. No que diz respeito ao Decreto 3.298/99, proposto no Brasil, a deficiência constitui-se por limitações que afetam a audição, a visão, a cognição, a dois ou mais desses sentidos e, por fim, áreas como mobilidade, flexibilidade, coordenação motora e percepção. 
De acordo com a Organização Mundial de Saúde (OMS), deficiência é o termo usado para definir a ausência ou a disfunção de uma estrutura psíquica, fisiológica ou anatômica. Segundo Carvalho-Freitas (2009), a deficiência é entendida como a alteração completa ou parcial de um ou mais segmentos do corpo humano que, em função de contingências históricas, sociais e espaciais, poderá resultar em perda de autonomia para a pessoa. Além dessa perda de autonomia, há outros resultados tão impactantes quanto a discriminação social.

Tem-se verificado que as necessidades e os direitos das pessoas com deficiência têm sido uma prioridade na agenda das Nações Unidas e, após anos de esforços, a Convenção das Nações Unidas sobre os Direitos das Pessoas com Deficiência e seu Protocolo Facultativo foram adotadas em 2006 e entraram em vigor em 3 de maio de 2008.

A UN Enable - que reúne o Secretariado da Convenção e dá voz ao compromisso das Nações Unidas de defender os direitos e a dignidade das pessoas com deficiência descreve o documento como um marco para uma mudança de paradigma, deixando de lado o fato de as pessoas com deficiência serem vistas como objetos de caridade, para visualizá-las como portadoras de direitos. E, como tal, são capazes de reivindicar os direitos e a tomada de decisões para as suas vidas com base em seu consentimento livre e esclarecido, bem como de serem membros ativos da sociedade.

A legislação brasileira também tem se detido em conceituar o que seja uma pessoa com deficiência e em estabelecer uma relação desse indivíduo com o trabalho. A Constituição Federal do Brasil, de 1988, traz como princípios a igualdade e dignidade humanas, organiza o Estado brasileiro, define os direitos dos cidadãos e trata diretamente das pessoas com deficiência em vários artigos, realçando, no artigo 24, que compete à União, aos estados e ao Distrito Federal legislar sobre a proteção e integração social das pessoas com deficiência (BRASIL, 1988). Já o artigo 208 realça que é dever do Estado promover 0 atendimento educacional especializado aos portadores de deficiência, preferencialmente na rede regular de ensino.

Em 1991, o Decreto n. 129, de 22/05/1991, dispôs sobre o que define pessoa portadora de deficiência com o foco na questão de empregabilidade (BRASIL, 1991). Em 1993, o Decreto n. 914, de 06/09/1993, dispôs sobre o mesmo tema (BRASIL, 1993). Em 1999, o Decreto n. 3.298/99 regulamentou a Lei n. 7.853, de 24 de outubro de 1989, que dispõe sobre a Política Nacional para a Integração da Pessoa Portadora de Deficiência (BRASIL, 2001a) e, para efeitos desse decreto, é considerada pessoa portadora de deficiência a que se enquadra numa das seguintes categorias: deficiência física, deficiência auditiva, deficiência visual, deficiência mental, deficiência múltipla.

O Decreto n. 3.956, de 08/10/2001, traz um elemento novo, ou seja, a deficiência além do nível biológico, ao realçar que o limite da capacidade de exercer as atividades pode ser causado ou agravado pelo ambiente econômico e social. (BRASIL, 2001b)

A Portaria n. 1199, de 28 de outubro de 2003, aprova normas para a imposição da multa administrativa variável prevista no art. 133 da Lei n. 8.213, de 24 de julho de 1991, pela infração ao art. 93 da mesma Lei, que determina às empresas o preenchimento de cargos com pessoas com deficiência ou beneficiários, variando o percentual conforme 0 número de empregados (BRASIL, 2003).

Outro aspecto importante para se compreender esse tema diz respeito à distinção entre os termos inclusão e inserção. Fala-se de inserção quando se coloca dentro de uma situação ou de um ambiente, independentemente da criação de condições para propiciar a adaptação e aceitação das pessoas, enquanto a inclusão implica o cuidado com o outro, a adaptação, a aceitação pelos que vão conviver com a pessoa.

A inclusão irá requerer das empresas e da sociedade a adoção de valores tais como: diversidade humana, o respeito às diferenças, a disponibilidade para mudanças $e$ adaptações. As empresas que se propuserem a ser inclusivas deverão estar dispostas a 
seguir o caminho do investimento em compreensão técnica, diagnósticos de áreas e atividades possíveis de adaptação. Devem, ainda, promover a sensibilização da equipe para recebimento e inclusão efetiva das pessoas com deficiência, de modo a romper barreiras, conscientizar e possibilitar um convívio livre de segregações e discriminações. Para que haja a inclusão, é preciso cooperação.

É possível inferir, a partir das considerações feitas, que a lei pode garantir a inserção das pessoas com deficiência no mercado de trabalho, mas a inclusão desse sujeito é um processo mais complexo que requer uma interação e aceitação dele com seus pares.

Usando os termos de busca: pessoas com deficiência, inserção de deficientes no mercado de trabalho, autopercepção de pessoas com deficiência, trabalho e identidade, foram consultados os sites responsáveis pela produção acadêmica na área. No site da Capes, foram encontrados 243 trabalhos. No site Scielo, foram detectados 80 . Os anais do EnANPAD mostraram 41 resultados. As principais pesquisas encontradas e relacionadas ao tema do presente trabalho são mostradas a seguir.

Anache (1996) apresentou uma pesquisa que demonstrou que as pessoas com deficiência, mesmo estando preparadas para assumir um lugar no mercado de trabalho, encontravam dificuldades em comparação com os não deficientes. Barboza (2003) analisou as estratégias dos setores de recursos humanos para realizar a inserção de pessoas com deficiência em seus quadros de pessoal. $\mathrm{O}$ autor abordou aspectos ligados à motivação na empresa, à integração social das pessoas com deficiência e à legislação específica e apontou a necessidade de disseminar o conhecimento da legislação que ampara essas pessoas. Coincidentemente, é justamente no ano de 2003 que, no Brasil, a questão da inclusão de pessoas com deficiência obteve evidência no mundo empresarial, quando foram aprovadas normas que visavam à imposição de multas administrativas às empresas pelo não cumprimento do sistema de cotas.

Em 2004, Heinski analisou a representatividade que o trabalho tem para as pessoas com deficiência e fez um estudo sobre a inclusão dessas pessoas no trabalho. Vasconcelos (2005) constatou que o sistema de cotas, exigido por lei, não basta para garantir um número de vagas suficientes para as pessoas com deficiência e realçou que a formação profissional não é aceita no Brasil como uma tarefa essencial do Estado. Ainda, em 2005, pesquisa realizada por Tanaka e Manzini (2005) evidenciou que as empresas investigadas na época tinham pessoas com deficiência em seus quadros de pessoal em virtude da obrigatoriedade da lei e que os cargos assumidos por essas pessoas exigiam pouca qualificação e que o treinamento era realizado no próprio local de trabalho.

Oliveira, Araújo e Romagnol (2006) investigaram o sentido do trabalho na dinâmica psíquica e social das pessoas com deficiência. Já Carvalho-Freitas (2007) investigou como a deficiência é vista pelos gestores e pelas pessoas responsáveis pela inserção de pessoas com deficiência nas empresas e constatou que as empresas priorizam modificações nas condições de trabalho mais que as ações de sensibilização que assegurem a inserção. Dando prosseguimento a essa preocupação, a autora investigou, em 2011, as principais características do processo de socialização das pessoas com deficiência nas organizações sob as dimensões biográfica, relacional e organizacional. Essa adaptação da pessoa com deficiência no trabalho continua merecendo estudos, e este trabalho aponta um possível encaminhamento para o caso.

Violante (2011) constatou, em sua pesquisa, que as políticas empresariais priorizam a contratação de pessoas cujas deficiências não exijam modificações estruturais no ambiente de trabalho, ou representem aspectos favoráveis à produção.

Santos e Costa (2013), em seus estudos sobre as diferentes perspectivas destinadas à preparação e inserção das pessoas com deficiência no mercado de trabalho, constataram que essas pessoas estão tendo oportunidades de se qualificarem e se prepararem para uma colocação adequada, diferentemente do que acontecia antes. Chegaram, ainda, à 
conclusão de que boa parte da contratação de pessoas com deficiência ocorre por causa do cumprimento de cotas.

Garcia (2014) verificou haver uma participação muito baixa das pessoas com deficiência no mercado de trabalho formal no Brasil e, onde ocorre, concentra-se em atividades precárias, descontínuas e informais, existindo ainda o caso de as pessoas ficarem inativas, sem exercerem uma ocupação.

Este trabalho, mesmo perpassando essas abordagens, se deteve no estudo de um público especial que é o jovem aprendiz com deficiência. Nesse sentido, pode-se afirmar que está sendo abordada uma nova faceta sobre a questão das pessoas com deficiência, ou seja, de que modo o preparo pode interferir na sua inclusão no mercado de trabalho, como essas pessoas se percebem e como são percebidas pelos seus pares. É oportuno lembrar que a maneira de se perceber constitui um fator relevante para a construção da identidade e que a inclusão no mercado de trabalho influencia de modo significativo a autopercepção da pessoa com deficiência.

\section{A pesquisa realizada}

A pesquisa realizada adotou uma abordagem qualitativa, visando analisar como as pessoas com deficiência, que participaram do programa de aprendizagem, percebem a sua entrada no mercado de trabalho. Buscou-se analisar, também, a percepção de gestores e colegas de trabalho sobre a chegada dessas pessoas na organização. Quanto aos fins, a pesquisa foi descritiva e, quanto aos meios, constituiu um estudo de caso.

A unidade de análise deste trabalho foi uma empresa de grande porte, situada na região metropolitana de Belo Horizonte, e os sujeitos de pesquisa foram oito gestores dos 14 atuantes na empresa; nove jovens com deficiência, dos 20 participantes do Programa Jovens Aprendizes; sete colegas de trabalho de um universo de 20 colaboradores que trabalham diretamente com esses jovens. Todas as pessoas foram submetidas a entrevistas semiestruturadas, que foram gravadas, transcritas e analisadas a partir de categorias definidas para cada grupo de entrevistados.

Os jovens aprendizes que compuseram a amostra apresentavam deficiência auditiva, visual e mental. Os gestores e colegas de trabalho foram pessoas que conviveram com esses jovens em situação de trabalho. Os critérios para a inclusão no estudo previam que os jovens entrevistados se expressassem em linguagem inteligível e que tivessem participado do Projeto Jovens Aprendizes 2012/2013.

Visando preservar a identificação dos jovens entrevistados neste estudo, foram usadas as seguintes denominações para eles: JV, BJ, RG, RS, AL, WV, WS, EH e IC. Os gestores foram identificados com a inicial $G$ e um numeral, variando de $G 1$ a $G 8$, e os colegas de trabalho com a inicial $C$ e sua identificação variou de $C 1$ a $C 7$.

Por questões de logística, as entrevistas do Projeto Jovens Aprendizes com deficiência foram realizadas na sede da empresa e imediatamente após o término do contrato da turma 2012/2013. Com roteiro previamente formulado, as perguntas tiveram como foco a investigação sobre a importância do trabalho para as pessoas com deficiência e o significado do Projeto Jovens Aprendizes na vida deles. As entrevistas com gestores e colegas de trabalho também foram realizadas na sede da empresa, com roteiro previamente formulado, e tinham como objetivo avaliar como eles percebiam a atuação das pessoas com deficiência na empresa.

As categorias definidas para o roteiro aplicado aos jovens foram as seguintes:

- Categoria 1 - O significado da participação no Projeto;

- Categoria 2 - A aprendizagem obtida durante o Projeto;

- Categoria 3 - A relação com os colegas de trabalho. 


\title{
3.1. Categoria - O significado da participação no Projeto
}

Tomando as entrevistas, verificou-se que os sujeitos de pesquisa assim argumentaram sobre o significado do Projeto.

\begin{abstract}
"Gostei. Amadureci muita coisa. Não queria trabalhar e aprendi a gostar. Na época, eu fiquei com preguiça e hoje, não" (WV).

"Gostei muito, aprendi muitas coisas, não sabia mexer com informática, arquivo. Ao receber o certificado, fiquei nervoso" (JV).

"Não sei assinar meu nome, minha mão treme, mas aqui melhorei isso. Agradeço por tudo que me ensinaram, agora é dar oportunidade para os outros. Se eu pudesse voltar, eu voltaria, mas não pode. Fico só ouvindo música porque não tou fazendo nada. Muita saudade" (JV).
\end{abstract}

Sennet (2008) considera a centralidade do trabalho na vida do indivíduo como instrumento de legitimação e reconhecimento. Corroborando tal observação, algumas falas ilustram como a participação no Projeto Jovens Aprendizes foi importante para promover condições de desenvolvimento da cidadania, legitimação e reconhecimento. Por outro lado, a fala do jovem JV evidencia que o dispositivo da lei não garante a permanência das pessoas com deficiência no mercado de trabalho. Os relatos indicam que não houve ascensão dentro da empresa, mas constata-se que já houve um avanço e conquista por parte desses jovens, sentimento de pertencimento e utilidade conquistados por meio do trabalho. Observa-se em seus relatos a satisfação pela participação e conquistas.

\footnotetext{
"Foi uma experiência boa. Aprendi a andar sozinha, ia pro curso e ficar aqui sozinha. Ah, mas as pessoas daqui são mais novas que eu, ficava com vergonha. Aprendi muito com as meninas" (AL).

"E eu nem andava sozinha e a minha mãe que me trazia. Depois, aprendi a vir sozinha. Falei que conseguia ir embora sozinha. Aprendi a conviver com as outras pessoas. Eu era muito fechada e depois comecei a conversar com todo mundo" (RG).
}

"Me senti mais importante porque, quando a gente trabalha, as pessoas se
interessam mais pelo que fazemos. Tive atividades que todo mundo faz,
computador, e demonstrei a mesma atitude que o pessoal tinha" (RS).

"Oportunidade de trabalhar fora da APAE, a primeira oportunidade. Estudar no SENAC. Ainda mais ganhando o meu próprio dinheiro e não depender dos outros" (WS).

As falas demonstraram que a superproteção da família, por receio de tratamentos hostis, não permite que a pessoa com deficiência lide com os acontecimentos da vida social. Tal atitude vai repercutir no comportamento dessas pessoas dentro do contexto de trabalho. Entretanto, com o trabalho, as pessoas com deficiência adquirem dignidade e controle sobre sua vida. Para essas pessoas, estar empregada e conservar o emprego representam o quanto ela está ajustada socialmente (SHAKESPEARE apud HEINSKI, 2004).

Machado (2003) esclarece que o conceito de si é uma construção mental complexa, fruto de uma relação dialética que considera o indivíduo igual a seus pares, mas único na sua existência, na sua experiência e vivência pessoal. Todos os entrevistados relataram que experimentam condições de valorização, desenvolvimento da cidadania, autoestima, dignidade e consciência. As respostas dadas às perguntas 
mostram como o jovem se sente reconhecido no trabalho e como este trabalho gera oportunidades para o estabelecimento de novas relações.

Os entrevistados afirmaram que foram muitas as conquistas de aprendizagem durante o período em que estiveram como participantes do Projeto de Jovens Aprendizes. O Projeto teria proporcionado oportunidades até então inimagináveis para alguns e, para outros, a concretização de um sonho e a possibilidade de se afirmarem como sujeitos ativos e participantes de um novo contexto, diferente do familiar e escolar até então vivenciado. Confirma-se o que Aranha (2003) enfatiza: o trabalho constitui fator determinante de autoestima, consciência e dignidade. Santos e Prado (2013) completam que o trabalho para tais pessoas envolve aspectos como autoestima, prazer, autorrealização, autonomia e possibilidade de conviver com outras pessoas, o que representa uma importante fonte de aceitação e, principalmente, de "humanização".

\subsection{Categoria - A aprendizagem obtida durante o projeto}

De acordo com Ribas (2008), a empregabilidade vai além de se oferecer um emprego para as pessoas com deficiência porque a legislação obriga; ela deve englobar ações de inclusão e permanência, com perspectivas de ascensão profissional e desenvolvimento. A falta de qualificação profissional tem sido um obstáculo à entrada das pessoas com deficiência nas empresas. Tanaka e Manzini (2005) realçam que um aspecto que dificulta a inserção da pessoa com deficiência no trabalho é a falha no processo de formação profissional.

O Projeto Jovens Aprendizes, da empresa investigada, tem o intuito de promover o aprendizado e a vivência dos jovens no mundo corporativo, possibilitando aos que participarem um preparo prévio e uma profissionalização para a entrada no mercado de trabalho, atrelado a sua obrigação no cumprimento de cotas, tanto de jovens aprendizes, quanto de pessoas com deficiência. As respostas dos jovens entrevistados expõem como eles se referem ao que obtiveram de aprendizado.

"Aprendi a mexer mais ainda no computador, tirar Xerox, arquivo. Ajudava a Rafaela com os livros, montar planilhas" (RG).

"Aprendi a montar planilhas, tirar Xerox de documentos, acompanhar as entrevistas e saber corrigir as provas. Atender as ligações" (RS).

"Nossa, levar documentos para outros setores, fazer AR, Xerox, pegava candidatos da XXX e levava pra sala. Fiz planilhas no computador" (AL).

"Eu gosto de escanear documentos, digitar os nomes no computador, levar correspondências, levar livros da XXX (plano de saúde) para outras áreas" (IC).

Constata-se que todos afirmam terem adquirido novos conhecimentos, desenvolvido novas habilidades e ainda mostram uma atitude positiva em relação à possibilidade de utilizar o que aprenderam em trabalho futuro. No contexto de inclusão de pessoas com deficiência, este programa de aprendizagem se apresenta como um facilitador para o desempenho de uma determinada função, propiciando uma qualificação para os participantes e uma possível colocação futura no mercado de trabalho. Bordignon e Sarmento (2011) realçam que a capacitação profissional permite que as pessoas com deficiência possam exercer funções mais bem remuneradas, pois é comum elas ocuparem vagas que exigem pouca qualificação.

Pessoas com deficiência geralmente não conseguem obter um emprego porque não têm a formação requerida. As contratações são eventuais e nem sempre compatíveis 
com as reais potencialidades, sem perspectivas de ascensão na empresa (HEINSKI; BIGNETTI, 2002).

\subsection{Categoria - Relação com os colegas de trabalho}

De acordo com Aranha (2003), é no contexto das relações sociais do trabalho que o homem se torna sujeito. Na medida em que modifica a realidade, transforma-se e constrói sua identidade pessoal e social. À parte as considerações práticas de ter dinheiro para viver e garantir sustento, para a pessoa com deficiência o fato de estar empregado contribui para elevar seu amor próprio, ajuda a evitar o tédio e aumenta contato com outras pessoas (SHAKESPEARE apud HEINSKI; BIGNETTI, 2002).

Foram respostas à questão que avaliava a relação com os colegas de trabalho.

"Era muito bom. A gente brincava. Todo dia conversava com todo mundo" (JV).

"Era muito bom. Gostei muito da Sula, do Tiago" (BJ).

"Renata é como amiga e mãe. Vocês também são minhas amigas, adorava conversar. Na hora do lanche, discutíamos os trabalhos dos outros" (RS).

Como se pode deduzir pelos relatos, durante o processo de aprendizagem, vão se formando vínculos, relações afetivas vão se efetivando, o grupo vai se firmando.

\footnotetext{
"Era muito bom. Eu gostava muito. Eles me davam muito conselho" (AL).

"Muito bom. Conversava muito com eles" (WV).

"Muito boa. Tudo o que me pedia, eu fazia, o Renato e o Bernardo" (WS).

"Eu gosto do Wanderson, que é meu parceiro, da Érica - vou sentir saudade, a Kênia e a Jéssica são minhas amigas. Gosto de tomar o café da D. Maria. O relacionamento era muito bom" (IC).
}

Conforme relata Glat (1995), embora seja possível fazer cumprir a lei de cotas, não se pode fazer com que as pessoas com deficiência sejam aceitas e que os demais as acolham com amizade. Entretanto, pela fala dos entrevistados, essa barreira foi vencida durante a preparação, sendo asseguradas maneiras e formas de interação com os demais funcionários.

Os jovens aprendizes relataram experimentar satisfação na convivência com os demais colegas, pois alegam bom relacionamento. Por outro lado, a boa receptividade por parte dos colegas veio garantir a inclusão desses jovens no ambiente de trabalho.

Nesse sentido, a realidade encontrada corrobora a afirmação de Heinski e Bignetti (2002), segundo os quais, a inclusão da pessoa com deficiência no mercado de trabalho é um processo que requer atitudes e iniciativas de todos os atores envolvidos: os deficientes, as empresas e a sociedade. De acordo com Vieira (2007), a posição em um grupo de trabalho e o reconhecimento desse lugar social pelo grupo influenciam a formação da identidade do indivíduo. Logo, todos aqueles envolvidos no processo de desenvolvimento do aprendiz, sejam eles os instrutores, os gestores ou os companheiros de trabalho, exercem um papel relevante na formação da identidade dos participantes.

Os gestores e colegas de trabalho dos jovens aprendizes também foram ouvidos e sua visão a respeito da inclusão das pessoas com deficiência no trabalho foi registrada.

"Vivemos hoje um quase apagão de mão de obra e existe um grande contingente de pessoas alijadas do trabalho por falta de qualificação. Boa parte dessas pessoas possui alguma deficiência, que pode impedi-las de desenvolver determinadas tarefas, mas não todas elas" (G1). 
Este entrevistado aponta um aspecto importante, que é a falta de qualificação das pessoas com deficiência, aspecto que o Projeto Jovens Aprendizes procura atender.

\begin{abstract}
"Com certeza, além de ser um dever constitucional, traz para as pessoas que são inseridas, maior autoestima, responsabilidades, desenvolve relacionamento em grupos, desenvolvimento de habilidades, fortalece a cidadania, independência, traz crescimento, aprendizado, autoconfiança e responsabilidade profissional e pessoal, enfim amadurecimento. Mediante a este trabalho produtivo o deficiente poderá se integrar de melhor forma na sociedade" (G2).
\end{abstract}

"É importante que as empresas auxiliem o poder público, completando o ciclo de inserção das pessoas com deficiência no mercado de trabalho, disponibilizando cargos e posto de trabalho adequado" (G3).

O entrevistado G4 chama a atenção para outro aspecto importante, que é o preconceito e sugere que as empresas o enfrentem para obterem bons resultados. Já os entrevistados G5 e G7 lembram que, por meio do trabalho, as pessoas com deficiência recuperam a dignidade e têm oportunidade de desenvolvimento.

"Meu sentimento é que ainda existe preconceito e desinformação entre as pessoas e falta de preparo e engajamento das empresas" (G4).

"Além de uma questão legal, a inclusão de pessoas com deficiência promoverá a inclusão social dessas pessoas. Conforme previsto na $\mathrm{CF} / 88$, o trabalho é um dos meios mais importantes para a promoção da dignidade humana" (G5).

"A inclusão de PcDs proporciona a essas pessoas uma oportunidade de desenvolvimento e crescimento na carreira profissional e na vida pessoal" (G7).

Os gestores citados a seguir também realçam os benefícios que a inclusão no trabalho traz para as pessoas com deficiência e para os demais funcionários.

"Todas as empresas têm o compromisso do capital social. Não podem existir sem o olhar para a sociedade onde estão inseridas. Dentro desta visão, cada empresa deve promover a inserção de pessoas com deficiências. Quando as empresas promovem programas de inclusão bem estruturados, o ganho é para ambos" (G3).

"Sim. Pois, ao incluí-las, não estamos apenas ofertando um salário, mas também a oportunidade de se reabilitarem socialmente e psicologicamente, trazendo para a empresa uma vasta experiência" (G7).

O entrevistado G4 chama a atenção para ações primordiais para uma boa acolhida e promoção efetiva da inclusão: conscientização sobre a deficiência, esclarecimentos sobre o cumprimento de cotas e o preparo do ambiente.

"Primeiramente, faz-se necessária a conscientização dos colaboradores, visando à mudança de cultura e a preparação física do ambiente de trabalho" (G4).

"A questão envolvendo a inclusão de pessoas com deficiência deve ser tratada como uma forma de promoção social e, não apenas, o cumprimento de cotas" (G5).

Analisando a fala dos gestores, pode-se inferir que eles enxergam como positivo o movimento de inclusão de jovens com deficiência no ambiente de trabalho e observam que os jovens estão se adaptando gradualmente a tal ambiente. Todos realçaram a importância do preparo para o trabalho. Cabe lembrar o que afirma Heinski (2004), segundo o qual, os administradores pouco a pouco estão entendendo que a pessoa 
portadora de deficiência é capaz de exercer as atividades para as quais foi contratada, desde que as suas limitações físicas, visuais, auditivas ou mentais sejam respeitadas.

Os colegas de trabalho falaram como percebem a importância da inclusão de jovens com deficiência no ambiente corporativo.

\begin{abstract}
"Em minha opinião, a inclusão é algo muito válida e importante na nossa sociedade. Ela se trata, não somente de inserir o jovem deficiente no mercado de trabalho e, sim, de incluir ele no meio coorporativo. A inclusão contribui para um melhor desenvolvimento, tanto profissional, quanto pessoal do jovem deficiente. Ele aprende como se portar em um ambiente de trabalho e como realizar atividades com um prazo definido. A rotina trabalhista passa a fazer parte da vida desse jovem, fazendo com que ele possa ter uma melhor adaptação em um futuro emprego" (C1).
\end{abstract}

"Muito importante, pois através da inclusão destes jovens no meio de trabalho o ganho acontece para ambos os lados. A empresa em si se adapta, muda de hábitos e rotinas e se transforma. O aprendizado, tanto profissional, como emocional é muito rico. Para o jovem é a sensação de realmente fazer parte da sociedade e todas as suas responsabilidades, convívio com outras pessoas e crescimento profissional" (C2).

A fala dos entrevistados destaca a importância da socialização dos jovens aprendizes com deficiência e realça a possibilidade de eles se tornarem capacitados para o futuro.

"Acho muito importante, e não só para eles como forma de aprendizado e convívio. Mas para nós que os recebemos. A inclusão acima de qualquer coisa nos permite conhecer e, assim, quebrar preconceitos como o de que pessoas com deficiência são menos capazes ou, até mesmo, incapazes" (C3).

Além de chamar a atenção para a capacitação do jovem aprendiz e para sua socialização, o próximo entrevistado traz um elemento novo, que é a possibilidade de vivenciar os princípios citados por Sassaki (1999), para que haja a inclusão: aceitação das diferenças individuais, a valorização de cada pessoa, a convivência dentro da diversidade humana, a aprendizagem via cooperação.

"É um processo de extrema importância, já que a inclusão visa o desenvolvimento profissional e pessoal das pessoas deficientes, que sofreram durante muitos anos com a questão do preconceito e resistência por parte da sociedade" (C4).

O entrevistado C6 elenca os desafios e as barreiras encontradas para que se possa alcançar a inclusão, entre elas se destaca a ineficiência do Estado e medo da família.

\begin{abstract}
"Acredito que trabalhar com a inclusão de jovens com deficiência constitui um grande desafio. Atravessamentos advindos de várias direções: do próprio governo (que exige a inclusão, mas não propicia uma educação de qualidade e que proporcione uma qualificação básica aos jovens); da família (que inviabiliza a inclusão do jovem por vários motivos - medo e receio em expor o jovem, superproteção e insegurança, além, é claro, do medo de perder o benefício recebido do governo); do próprio jovem (que, às vezes, não se compromete com a atividade laboral e não se implica com o significado do trabalho por já estar habituado a receber um tratamento que o desqualifica enquanto um sujeito ativo e capaz de trabalhar); da sociedade (que estigmatiza o 'diferente'); da empresa (porque existem colaboradores que não estão comprometidos com a causa da inclusão, o que dificulta nossas intervenções a fim de promover o desenvolvimento profissional e pessoal desses jovens)" (C6).
\end{abstract}

Analisando as respostas dadas pelos colegas de trabalho, verifica-se que os pontos valorizados por eles quanto à inclusão do jovem com deficiência no mercado de 
trabalho são os seguintes: a) a inclusão é capaz de promover melhor desenvolvimento profissional e pessoal para o jovem; b) quando o jovem é preparado para as funções que virá a exercer no trabalho, ele tem maior segurança; c) a inclusão representa ganhos, tanto para empresa, quanto para o jovem aprendiz no quesito aprendizagem, desenvolvimento, convívio e crescimento profissional. Além disso, eles consideram que a inclusão das pessoas com deficiência propicia a quebra de modelos mentais preconceituosos.

Concluindo essa análise, infere-se que os relatos feitos pelos entrevistados demonstram conscientização com relação à inclusão das pessoas com deficiência que vai além da determinação da legislação. Todos eles demonstraram motivos relevantes, que passam pela ética, responsabilidade social e respeito pelo próximo. O Instituto Ethos (2002) destaca que buscar trazer a diferença para dentro da empresa, combatendo o preconceito e reconhecendo a igualdade essencial entre as pessoas, é uma atitude que faz parte da postura ética a ser adotada como valor e prática nos negócios. O mesmo Instituto Ethos (2002) ainda elucida que a empresa inclusiva reforça o espírito de equipe de seus funcionários, fortalecendo a sinergia em torno dos objetivos comuns e expressando seus valores coletivamente.

Os colegas de trabalho relataram como se dá a interação com os jovens com deficiência no ambiente de trabalho.

\begin{abstract}
"No início, encontrei algumas dificuldades, por exemplo, como me referir a deficientes visuais, como falar com deficientes auditivos, como cobrar o que é necessário na hora certa entre outras. Na medida em que o tempo foi passando, fui acostumando e tratando a situação como algo natural, me relacionando melhor com os jovens. Entendi que eles também devem ser cobrados e que têm um prazo a cumprir. Devemos adaptar o ambiente para recebê-los da melhor forma possível, para que o trabalho se torne algo prazeroso e rotineiro na vida desses jovens" (C5).

"É um grande aprendizado; pude atentar a detalhes que contribuem bastante pra inserção dos deficientes" (C4).

"Acredito que, no início, todos nós, colaboradores, tivemos dificuldades em lidar com os jovens, uma vez que cada um tem uma limitação e comprometimento específico. Contudo, o mais importante é o aprendizado que temos a cada turma que inicia na empresa. Já progredimos muito e ainda evoluiremos bastante em todos os sentidos. É impossível não considerarmos as limitações e potencialidades dos jovens ao delegarmos atividades a eles, pois é a partir disso que promovemos a inclusão: aproveitando a potencialidade e habilidade do jovem a fim de que encontre a profissão que desejar" (C6).
\end{abstract}

Os entrevistados chamam a atenção para a necessidade de se entender como lidar com os diferentes tipos de deficiência para melhor rendimento desses jovens. Entretanto, declaram que a inclusão ocorre de maneira tranquila sem maiores intercorrências. Foi lembrada, com muita propriedade, a necessidade de se efetuar a avaliação de competências dos jovens aprendizes antes de encaminhá-los para o desempenho das diferentes tarefas.

"Depende muito da deficiência de cada jovem aprendiz contratado. Por isso, a avaliação de competências prévia é muito importante antes da escolha do setor a encaminhar, no caso do meu setor, os jovens têm ajudado bastante no desenvolvimento de tarefas mais operacionais e/ou rotineiras que demandam muito tempo" (C5).

Algumas falas dos entrevistados vão confirmar a afirmação de Bittencourt e Fonseca (2011), quando as autoras esclarecem que a falta de informações sobre a deficiência, o desconhecimento do potencial desses indivíduos, a crença de que as 
pessoas com deficiência não irão corresponder aos resultados esperados pela empresa dificultam a absorção dessa mão de obra. Uma vez superadas essas barreiras e acrescido o respeito às limitações de cada um, pode-se concluir que o jovem com deficiência, se bem preparado, pode trazer uma contribuição valiosa para a organização.

Quanto ao Projeto Jovens Aprendizes com foco no recrutamento de jovens com deficiência, a pesquisa permitiu concluir que tal iniciativa tem propiciado a inclusão das pessoas com dignidade, trazendo benefícios pessoais, profissionais e sociais. No quesito capacitação, acredita-se que o Projeto contribuirá, no futuro, para melhor empregabilidade do jovem com deficiência.

\section{Considerações finais}

Convive-se, atualmente, com uma nova visão das possibilidades das pessoas com deficiência. Diferentemente de outros momentos da História, nos tempos atuais, considera-se que essas pessoas podem e devem ser inseridas no mercado de trabalho e que isso trará consequências para sua autopercepção, elevará sua autoestima e dará contribuições relevantes para a construção de sua identidade.

Esta pesquisa buscou analisar de que maneira ocorriam a inclusão e o desenvolvimento de jovens aprendizes com deficiência no mercado de trabalho de uma empresa da região metropolitana de Belo Horizonte. Pretendeu-se contribuir para o aprimoramento do entendimento da sociedade sobre a deficiência e como o trabalho pode contribuir para mudanças na vida das pessoas com deficiência.

Os resultados foram alcançados a partir da análise das percepções dos jovens com deficiências participantes do Projeto Jovens Aprendizes, somados à análise das percepções de gestores e colegas de trabalhos desses jovens. Buscou-se identificar como os jovens aprendizes avaliam o significado do curso feito, a contribuição trazida por eles, às dificuldades encontradas e sua adaptação ao trabalho.

Uma constatação que merece destaque é que programas de aprendizagem para jovens com deficiência propiciam o convívio desses jovens com outras pessoas, contribuindo para sua socialização. Tal resultado confirma a afirmativa de Machado (2003), segundo a qual, embora exista em cada indivíduo um senso de individualidade, a construção do autoconceito, baseada nas experiências de socialização, constitui o principal referencial para a formação das identidades.

Constatou-se que a empresa investigada desenvolve um trabalho relevante, uma vez que vem tentando conscientizar a todos sobre a importância de se promover a inclusão social das pessoas com deficiência. Buscando promover a qualificação dessas pessoas, a empresa tem contribuído para efetivar o convívio sem discriminação, a quebra de paradigmas e a construção de um novo modelo mental, que possibilita à pessoa com deficiência a aprendizagem, a entrega ao seu trabalho e o reconhecimento pelos resultados alcançados com seu trabalho.

Foi possível concluir, também, que a empresa investigada enfrenta dificuldades para adaptar e promover a socialização de alguns jovens com deficiência, como se depreende do relato dos gestores e dos colegas de trabalho. Infere-se que ainda há muito que aprender para efetivar a inclusão verdadeiramente.

O Projeto Jovens Aprendizes investigado corrobora a afirmação de Vasconcelos (2005) de que a criação das cotas tem ampliado o mercado de trabalho e motivado iniciativas de qualificação profissional, embora por meio de um modelo de educação profissional não articulado à rede regular de educação e quase sempre resultante de iniciativas de organizações não governamentais sem apoio do Estado. 


\section{Referências}

ANACHE, A. A. O deficiente e o mercado de trabalho: concessão ou conquista? Revista Brasileira de Educação Especial, Marília, v. 2, n.4, p.119 a 26, 1996.

ARANHA, M. S. F. Trabalho e emprego: instrumento de construção da identidade pessoal e social. Presidência da República, Secretaria Especial dos Direitos Humanos, 2003.

BARBOZA, F. V. Estratégias de recursos humanos pra incluir a pessoas portadora deficiência no mercado de trabalho. 2003, 96 f. Dissertação (Mestrado em Administração de Empresas) - Centro Universitário Álvares Penteado da Fundação Escola de Comércio Álvares Penteado - UNIFECAP -. São Paulo

BATISTA, C. A. M. Inclusão: construção na diversidade. Belo Horizonte: Armazém de Ideias, 2004.

BITTENCOURT, Z. Z. L. C.; FONSECA, A. M. R. Percepções de pessoas com baixa visão sobre seu retorno ao mercado de trabalho. Paidéia, Ribeirão Preto, v. 21, n. 49, p. 18795, ago. 2011.

BORDIGNON, P. M.; SARMENTO, D. F. Capacitação profissional de pessoas com deficiência: um estudo de caso no Secap/Faders. Boletim Técnico do Senac: revista da Educação Profissional, Rio de Janeiro, v. 37, n. 1, p. 34-47, jan./abr. 2011.

BRASIL. Constituição Federal de 1988. Promulgada em 5 de outubro de 1988. Disponível em: <http://www.planalto.gov.br/ccivil_03/constituicao/constituição.htm>. Acesso em: 30 jun. 2013.

BRASIL. Decreto n. 129 de 22 de Maio de 1991. Promulga a Convenção n. 159, da Organização Internacional do Trabalho (OIT), sobre a reabilitação profissional e emprego de pessoas deficientes. Brasília: DOU, 1991

BRASIL. Decreto n.914 de 06 de Setembro de 1993. Institui a Política Nacional para a Integração da Pessoa Portadora de Deficiência, e dá outras providências. Brasília: DOU, 1993.

BRASIL. Decreto n. 3.298 de 20 de Dezembro de 1999. Regulamenta a Lei n. 7.853, de 24 de outubro de 1989, dispõe sobre a Política Nacional para a Integração da Pessoa Portadora de Deficiência, consolida as normas de proteção, e dá outras providências. Brasília: DOU, 1999.

BRASIL. Decreto n. 3.956 de 08 de Outubro de 2001. Promulga a Convenção Intramericana para eliminação de todas as formas de discriminação contra as pessoas portadoras de deficiência. Brasília: DOU, 2001.

BRASIL. Portaria n. 1199, de 28 de outubro de 2003. Aprova normas para a imposição da multa administrativa variável prevista no art. 133 da Lei n. 8.213, de 24 de julho de 1991, pela infração ao art. 93 da mesma Lei, que determina às empresas o preenchimento de cargos com pessoas portadoras de deficiência ou beneficiários reabilitados. Disponível em: <http://portal.mte.gov.br/legislacao/portaria-n-1-199-de-28-10-2003.htm> Acesso em: 30 jun. 2013. 
CARVALHO-FREITAS, M. N. Análise da inserção e gestão do trabalho de pessoas com deficiência: um estudo de caso. In: ENCONTRO ANUAL DA ASSOCIAÇÃO NACIONAL DE PÓS-GRADAÇÃO EM ADMINISTRAÇÃO. 2007, Rio de Janeiro. Anais... Rio de Janeiro: ENAP, 2007. CD-Rom.

CARVALHO-FREITAS, M. N. A inserção e gestão do trabalho de pessoas com deficiência: um estudo de caso. Revista de Administração Contemporânea, Curitiba, v. 13, n. 8 p. 121-38, jun. 2009.

CARVALHO-FREITAS, M. N.; MARQUES, A. L. Formas de ver as pessoas com deficiência: um estudo empírico do construto de concepções de deficiência em situações de trabalho. Revista de Administração Mackenzie, São Paulo, v. 11, n. 3, p. 100-29, mai./jun. 2010a.

CARVALHO-FREITAS, M. N.; MARQUES, A. L. Inserção de pessoas com deficiência em organizações brasileiras: um estudo com empresas socialmente responsáveis. Revista Eletrônica de Gestão Organizacional, Recife, v. 8, n. 3, p. 483-502, set./dez. 2010 b.

GARCIA, V. G. Panorama da inclusão das pessoas com deficiência no mercado de trabalho no Brasil. Trabalho Educação e Saúde, Rio de Janeiro, v. 12, n. 1, p. 165-187, jan./abr. 2014.

GLAT, R. A integração social dos portadores de deficiência: uma reflexão. Rio de Janeiro: Sette Letras, 1995, v. 1.

HEINSKI, R. M. M. S; BIGNETTI, L.P. A inclusão de pessoas portadoras de deficiência no mercado de trabalho. Cladea, 2002. Porto Alegre. Anais eletrônicos. 2002

HEINSKI, R M M. Um estudo sobre a inclusão da pessoa portadora de deficiência no mercado de trabalho. In: ENCONTRO NACIONAL DE PÓS-GRADUAÇÃO E PESQUISA EM ADMINISTRAÇÃO-ENANPAD. 28, 2004, Curitiba. Anais... Curitiba: ANPAD, 2004

INSTITUTO ETHOS O que as empresas podem fazer pela inclusão das pessoas com deficiência. GIL, M. (Coord). - São Paulo: Editora, 2002.

LOPES, G. G. V. A inserção do portador de deficiência no mercado de trabalho: a efetividade das leis brasileiras. São Paulo: LTr, 2005.

LORENTZ, L. N. A norma da igualdade e o trabalho das pessoas portadoras de deficiência. São Paulo: LTR, 2006.

MACHADO, H. V. A identidade e o contexto organizacional: perspectivas de análise. Revista de Administração Contemporânea, Rio de Janeiro, v. 51 , n. 73 , p. 51- 73, 2003.

MENDONÇA, L. E. A. Lei de cotas - pessoas com deficiência: a visão empresarial. São Paulo: LTR, 2010.

OLIVEIRA, J. M.; ARAÚJO, J. N. G.; ROMAGNOLI, R. C. Dificuldades relativas à inclusão social das pessoas com deficiência no mercado de trabalho. Latin-American Journal of fundamental psychopathology . v. 6, n. 1, p. 77-89, 2006. 
OLIVEIRA, M. A.; GOULART-JÚNIOR, E.; FERNANDES, J. M. Pessoas com deficiência no mercado de trabalho: considerações sobre políticas públicas nos Estados Unidos, União Europeia e Brasil. Revista Brasileira de Educação Especial, Marília, n. 15, v. 2, p. 219-32, maio./ago. 2009.

RIBAS, J. B. C. Por que empregar pessoas com deficiência. In: CARVALHO-FREITAS, MN e MARQUES, AL (Orgs). Trabalho e pessoas com deficiência: pesquisas, práticas e instrumentos de diagnóstico. Curitiba: Juruá, 2008, p. 211-217.

SANTOS, A.C.; COSTA, M.P.R. Diferentes perspectivas sobre a preparação e inserção da pessoa com deficiência no mercado de trabalho. In: VIII ENCONTRO DA ASSOCIAÇÃO BRASILEIRA DE PESQUISADORES EM EDUCAÇÃO ESPECIAL, Londrina, 2013, anais... Londrina: UEL, 2013.

SANTOS, T. L. B.; PRADO, A. S. Empresa inclusiva? Uma análise comparativa dos discursos de dirigentes e trabalhadores com deficiência de uma empresa cooperativa [Abstract]. In: ENCONTRO NACIONAL DE PÓS-GRADUAÇÃO E PESQUISA EM ADMINISTRAÇÃO, 38., 2013, Rio de Janeiro. Anais... Rio de Janeiro: ANPAD, 2013.

SASSAKI, R.K. Inclusão: construindo uma sociedade para todos. Rio de Janeiro: WVA, 1999.

SASSAKI, R. K. Como chamar as pessoas que têm deficiência? Revista da Sociedade Brasileira de Ostomizados, v. 1, n.1, p. 8-11, jan./jul. 2009.

SECRETARIA INTERNACIONAL DO TRABALHO. Gestão de questões relativas à deficiência no local de trabalho: repertório de recomendações práticas da OIT. Tradução de Edilson Alkmin Cunha. Revisão técnica de João Baptista Cintra Ribas.. Brasília: OIT, 2006.

SENNET, R. A corrosão do caráter - consequências pessoais do trabalho no novo capitalismo. 13a ed., Rio de Janeiro: Record, 2008.

SUZANO, J. C. C et al. Análise da produção acadêmica nacional dos últimos 20 anos sobre a inserção da pessoa portadora de deficiência no mercado de trabalho. In: CARVALHO-FREITAS, M. N.; MARQUES, A. L. (Orgs). 0 trabalho e as pessoas com deficiência: pesquisa, práticas e instrumentos de diagnóstico. Curitiba: Juruá, 2008. p. 23-42.

TANAKA, E. D. O.; MANZINI, E. J. O que os empregadores pensam sobre o trabalho da pessoa com deficiência? Revista Brasileira de Educação Especial, Marília, v. 11, n. 2, p. 273-94, maio./ago. 2005.

VASCONCELOS, F. D. Ironias da desigualdade: políticas e práticas de inclusão de pessoas com deficiência física. 193 p, 2005. Tese (Doutorado em Saúde Coletiva) Instituto de Saúde Coletiva da Universidade Federal da Bahia. Salvador.

VIEIRA, A. Identidade e crise de identidade: reflexões conceituais. In: VIEIRA, A. e GOULART, I. B. (Orgs). Identidade e subjetividade na gestão de pessoas. Curitiba: Juruá, 2007, p. $55-72$. 
VIOLANTE, Rômulo Rodrigues; LEITE, Lúcia Pereira. A empregabilidade das pessoas com deficiência: uma análise da inclusão social no mercado de trabalho do município de Bauru, SP. Cadernos de Psicologia Social do Trabalho, São Paulo, v. 14, n. 1, p. 7391, jun 2011. 